\title{
The Assessment of Short IVF Protocols: Clinical Status and Success Rates Among Women Treated in IVF Center in Prince Rashid Hospital, Jordan
}

\author{
Mothanna Nazmi Jaber Nawafleh*, Raed Aref Mousa Sharadgah, Mohammed Fayez Bataineh, Alaa \\ Abdullah Al Sharman and Shirin Mahmmoud Imbark Alawadi \\ Royal Medical Services, Prince Rashid Hospital, Jordan \\ *Corresponding author: Mothanna Nazmi Jaber Nawafleh, Royal Medical Services, Prince Rashid Hospital, Jordan
}

\begin{tabular}{l}
\hline ARTICLE INFO \\
\hline Received: May 15, 2019 \\
Published: May 28, 2019 \\
\hline Citation: Mothanna Nazmi Jaber N, \\
Raed Aref Mousa S, Mohammed Fayez \\
B, Alaa Abdullah Al S, Shirin Mahmmoud \\
Imbark A. The Assessment of Short IVF \\
Protocols: Clinical Status and Success \\
Rates Among Women Treated in IVF \\
Center in Prince Rashid Hospital, Jordan. \\
Biomed J Sci \& Tech Res 18(3)-2019. \\
BJSTR. MS.ID.003148.
\end{tabular}

Keywords: Short Protocol; IVF; Oocyte; Embryo; Pregnancy; FSH; LH

\section{ABSTRACT}

Introduction: In clinical practice regarding the case of IVF treatment, short IVF protocols may be selected.

Objectives: to assess the influence of follicle stimulating hormone (FSH) and Luteinizing Hormone (LH) in the number of oocytes and the number of embryos; and to investigate a possible relationship of these hormones with rates of IVF success.

Methods and Patients: A retrospective design was conducted to collect data from files of female patients under treatment with IVF-short protocols. A total of 50 files of women who underwent for this treatment were included in this study. An excel sheet was used to enter the data for all included files. The data were analyzed using SPSS version 21.

Study Results: The success rate of pregnancy was 36\%. Age of participants was significantly associated with the level of LH ( $\mathrm{p}=0.035)$. The embryo number was significantly associated with pregnancy result $(\mathrm{p}=0.044)$. Age was negatively and significantly correlated with embryo No $(r=-0.337, p=0.017)$. Another positively and significantly correlation was computed between Oocyte No and embryo No ( $\mathrm{r}=0.582$, $\mathrm{p}=0.000$ ). A positively and significantly correlation was found between the result of pregnancy and embryo No ( $\mathrm{r}=0.286, \mathrm{p}=0.044)$.

Conclusion: The present study showed the success pregnancy rate was $36 \%$ following short IVF protocol. Success rate depended on the number of embryos.

\section{Introduction}

The main objective of conventional ovarian stimulation protocols regarding in vitro fertilization (IVF) is to obtain highest oocyte yields (Practice Committee of American Society for Reproductive Medicine, 2008). There are side effects associated with conventional protocols such as patient anxiety, ovarian hyperstimulation syndrome increased risk, and high financial expenses [1-3]. The idea of using mild stimulation protocols has recently been introduced and received acceptance [4]. In these protocols, low doses of exogenous gonadotrophins ( $<150$ IU/day) are used. The objective of these protocols is to minimize the retrieved oocytes to be less than eight. It has been reported that pregnancy rate is lower in short protocols compared with long protocols [5]. During the past years, the standard hormonal treatment was based on the agonists of gonadotropin-releasing hormone ( $\mathrm{GnRH}$ ) agonists accompanied by stimulation of ovary using exogenous gonadotropins. This approach was implemented for treatment of women in need for assisted reproductive technologies (ART) [6]. There have been improvements in the outcome of pregnancy as a result of using GnRH agonist in cases of controlled ovarian hyperstimulation $(\mathrm{COH})$ protocols. There is a lowered cycle cancellation by elimination of spontaneous LH surges as well as reduction of poor follicular development [7]. There are protocols for superovulation that can be categorized into three groups: ultra-short, the short and the long protocols [8]. The stimulation of follicles and their growth takes place through giving exogenous FSH. In short protocol, the initial stimulatory phase of GnRHa is 
used to improve the induction of follicles and keep a hyposecretion of endogenous gonadotropins to be involved in the follicular phase. Exogenous FSH is given to stimulate follicular growth [9].

\section{Study Objectives}

The main objectives of the present study were to assess the influence of follicle stimulating hormone (FSH) and Luteinizing Hormone (LH) in the number of oocytes and the number of embryos; and to investigate a possible relationship of these hormones with rates of IVF success.

\section{Methods and Subjects:}

Study Design: A retrospective design was conducted to collect data from files of female patients under treatment with IVF-short protocols.

Study Sample: A total of 50 files of women who underwent for this treatment were included in this study. Files with complete information were analyzed.

Study Variables: Study variables included demographic variables including age, hormone levels of $\mathrm{FSH}$, and LH, the number of oocytes, and embryos, and the result of IVF.

Statistical Analysis: An excel sheet was used to enter the data for all included files. The data was further analyzed using SPSS version 21. Data was presented as means and standard deviations. One Way Anova was used to investigate the effect of age on study variables, and to investigate the effects of study variables on pregnancy result. Pearson correlation was used to compute the correlation between study variables. The significance was considered at $\mathrm{p} \leq 0.05$.

\section{Results}

\section{General Characteristics of Study Participants}

As demonstrated in Table 1, the mean age of women in this study is $28.68 \pm 4.80$ years. The average of FSH is $5.52 \pm 1.73 \mathrm{IU} / \mathrm{L}$, and the average of $\mathrm{LH}$ is $5.08 \pm 3.24 \mathrm{IU} / \mathrm{L}$. the results also indicated that the average of Oocyte No is $6.54 \pm 2.57$, while the average of embryo No is $2.04 \pm 0.925$. The pregnancy success rate is $36 \%$.

Table 1: General characteristics of study participants.

\begin{tabular}{|c|c|}
\hline Variable & Description \\
\hline Age $(\mathrm{M} \pm \mathrm{SD})$ years & $28.68 \pm 4.80$ \\
\hline 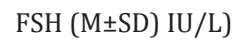 & $5.52 \pm 1.73$ \\
\hline $\mathrm{LH}(\mathrm{M} \pm \mathrm{SD}) \mathrm{IU} / \mathrm{L})$ & $5.08 \pm 3.24$ \\
\hline Oocyte NO (M士SD) & $6.54 \pm 2.57$ \\
\hline Embryo No $(\mathrm{M} \pm \mathrm{SD})$ & $2.04 \pm 0.925$ \\
\hline $\begin{array}{l}\text { Result (N, \%): } \\
\text { - } \quad \text { Pregnancy } \\
\text { - } \quad \text { No pregnancy }\end{array}$ & $\begin{array}{l}18(36 \%) \\
32(64 \%)\end{array}$ \\
\hline
\end{tabular}

\section{The Impact of Age on Study Variables}

The impact of age on study variable was investigated using One Way Anova test. As shown in Table 2, the level of LH was only significantly associated with age $(\mathrm{p}=0.035)$. The other variables were not impacted significantly by age $(\mathrm{P}>0.05)$.

Table 2: The impact of age on study variables (One Way Anova test).

\begin{tabular}{|c|c|c|c|c|c|c|}
\hline & & Sum of Squares & df & Mean Square & $\mathbf{F}$ & Sig. \\
\hline \multirow{3}{*}{ FSH } & Between Groups & 34.892 & 16 & 2.181 & .646 & .823 \\
\hline & Within Groups & 111.404 & 33 & 3.376 & & \\
\hline & Total & 146.296 & 49 & & & \\
\hline \multirow{3}{*}{ LH } & Between Groups & 246.256 & 15 & 16.417 & 2.148 & .035 \\
\hline & Within Groups & 236.964 & 31 & 7.644 & & \\
\hline & Total & 483.219 & 46 & & & \\
\hline \multirow{3}{*}{ Oocyte No } & Between Groups & 152.491 & 16 & 9.531 & 1.829 & .070 \\
\hline & Within Groups & 171.929 & 33 & 5.210 & & \\
\hline & Total & 324.420 & 49 & & & \\
\hline \multirow{3}{*}{ Embryo No } & Between Groups & 16.522 & 16 & 1.033 & 1.342 & .231 \\
\hline & Within Groups & 25.398 & 33 & .770 & & \\
\hline & Total & 41.920 & 49 & & & \\
\hline
\end{tabular}

\section{The impact of Study Variables on Pregnancy Result}

As shown in Table 3, the impact of study variables on pregnancy results was investigated through One Way Anova test. The only variable that was statistically significant on the pregnancy result was the Embryo No $(p=0.044)$. The other variables were not statistically significantly associated with pregnancy result $(p>0.05)$. Correlation between study variables. As shown in
Table 4 , the correlation between study variables was computed using Pearson correlation. Age was negatively and significantly associated with embryo No ( $\mathrm{r}=-0.337, \mathrm{p}=0.017)$. Another positively and significantly correlation was computed between Oocyte No and embryo No ( $r=0.582, p=0.000)$. Finally, a positively and significantly correlation was found between the result of pregnancy and embryo No $(r=0.286, p=0.044)$. 
Table 3: The impact of study variables on pregnancy result (One Way Anova test).

\begin{tabular}{|c|c|c|c|c|c|c|}
\hline Sum of Squares & df & Mean Square & $\mathbf{F}$ & Sig. & & \\
\hline \multirow{3}{*}{ FSH } & Between Groups & 3.632 & 1 & 3.632 & 1.222 & .275 \\
\hline & Within Groups & 142.665 & 48 & 2.972 & & \\
\hline & Total & 146.296 & 49 & & & \\
\hline \multirow{3}{*}{ LH } & Between Groups & 10.058 & 1 & 10.058 & .957 & .333 \\
\hline & Within Groups & 473.162 & 45 & 10.515 & & \\
\hline & Total & 483.219 & 46 & & & \\
\hline \multirow{3}{*}{ Oocyte No } & Between Groups & 3.423 & 1 & 3.423 & .512 & .478 \\
\hline & Within Groups & 320.997 & 48 & 6.687 & & \\
\hline & Total & 324.420 & 49 & & & \\
\hline \multirow{3}{*}{ Embry No } & Between Groups & 3.423 & 1 & 3.423 & 4.269 & .044 \\
\hline & Within Groups & 38.497 & 48 & .802 & & \\
\hline & Total & 41.920 & 49 & & & \\
\hline
\end{tabular}

Table 4: Correlation between study variables (Pearson correlation).

\begin{tabular}{|c|c|c|c|c|c|c|c|}
\hline & & age & FSH & LH & Oocyte No & Embryo No & Result \\
\hline \multirow[t]{3}{*}{ age } & $\begin{array}{l}\text { Pearson } \\
\text { Correlation }\end{array}$ & 1 & .052 & $-.138-$ & $-.230-$ & $-.337-*$ & $-.247-$ \\
\hline & Sig. (2-tailed) & & .719 & .356 & .108 & .017 & .084 \\
\hline & $\mathrm{N}$ & 50 & 50 & 47 & 50 & 50 & 50 \\
\hline \multirow[t]{3}{*}{ FSH } & $\begin{array}{l}\text { Pearson } \\
\text { Correlation }\end{array}$ & .052 & 1 & .162 & .080 & $-.105-$ & $-.158-$ \\
\hline & Sig. (2-tailed) & .719 & & .277 & .579 & .466 & .275 \\
\hline & $\mathrm{N}$ & 50 & 50 & 47 & 50 & 50 & 50 \\
\hline \multirow[t]{3}{*}{$\mathrm{LH}$} & $\begin{array}{l}\text { Pearson } \\
\text { Correlation }\end{array}$ & $-.138-$ & .162 & 1 & .048 & .277 & .144 \\
\hline & Sig. (2-tailed) & .356 & .277 & & .750 & .059 & .333 \\
\hline & $\mathrm{N}$ & 47 & 47 & 47 & 47 & 47 & 47 \\
\hline \multirow[t]{3}{*}{ Oocyte No } & $\begin{array}{l}\text { Pearson } \\
\text { Correlation }\end{array}$ & $-.230-$ & .080 & .048 & 1 & $.582^{* *}$ & .103 \\
\hline & Sig. (2-tailed) & .108 & .579 & .750 & & .000 & .478 \\
\hline & $\mathrm{N}$ & 50 & 50 & 47 & 50 & 50 & 50 \\
\hline \multirow[t]{3}{*}{ Embryo No } & $\begin{array}{l}\text { Pearson } \\
\text { Correlation }\end{array}$ & $-.337-*$ & $-.105-$ & .277 & $.582^{* *}$ & 1 & $.286^{*}$ \\
\hline & Sig. (2-tailed) & .017 & .466 & .059 & .000 & & .044 \\
\hline & $\mathrm{N}$ & 50 & 50 & 47 & 50 & 50 & 50 \\
\hline \multirow[t]{3}{*}{$\begin{array}{l}\text { Result of } \\
\text { pregnancy }\end{array}$} & $\begin{array}{l}\text { Pearson } \\
\text { Correlation }\end{array}$ & $-.247-$ & $-.158-$ & .144 & .103 & $.286^{*}$ & 1 \\
\hline & Sig. (2-tailed) & .084 & .275 & .333 & .478 & .044 & \\
\hline & $\mathrm{N}$ & 50 & 50 & 47 & 50 & 50 & 50 \\
\hline \multicolumn{7}{|c|}{ *. Correlation is significant at the 0.05 level (2-tailed). } & \\
\hline
\end{tabular}

\section{Discussion}

We conducted this study to assess the influence of follicle stimulating hormone (FSH) and Luteinizing Hormone (LH) in the number of oocytes and the number of embryos; and to investigate a possible relationship of these hormones with rates of IVF success. In this study, short protocols for IVF were followed. The results of this study showed that the success rate was $36 \%$. The number of oocytes was about 7. These findings are in line with previous studies [10-13] that reported the oocyte number to be less than 8 and also indicated less pregnancy rates compared with conventional methods. The results of the present study showed that age was significantly associated $\mathrm{LH}(\mathrm{p}=0.035)$. The other variables were not significantly with age $(\mathrm{p}>0.05)$. This finding agrees with other studies in which age $>35$ years may benefit from short protocols, but as patients become older, poor outcomes are expected [14- 
16]. The study findings showed that the number of embryos was significantly associated with pregnancy outcome. These findings are plausible and imply that increased number of embryos may lead to success rates of pregnancy; this is in agreement with previous studies [16,17].

Correlation analysis showed that age was negatively and significantly correlated with the number of embryos $(\mathrm{r}=-0.337$, $\mathrm{p}=0.017$ ). With increased age, the chance for IVF success becomes less. This is in agreement with other studies [18]. A positive and significantly correlation was found between oocyte number and embryo number $(\mathrm{r}=0.582, \mathrm{p}=0.000)$. This finding implies that the number of oocyte $(6.54 \pm 2.57)$ was a significant factor for embryo increased number and as a consequent increased success rate of pregnancy. This is in line with some previous studies $[19,20]$. A positive and significantly correlation was found between pregnancy results and embryo number $(r=0.286, p=0.044)$. As the number of embryo increases, it is more likely for the pregnancy to take place. This result is logic and in agreement with other studies [21].

\section{Conclusion}

The present study showed the success pregnancy rate was $36 \%$ following short IVF protocol. Success rate depended on the number of embryos.

\section{References}

1. Baker VL (2013) Mild ovarian stimulation for in vitro fertilization: one perspective from the USA. J Assist Reprod Genet 30(2): 197-202.

2. Bencomo E, Pérez R, Arteaga MF, Acosta E, Peña O, et al. (2006) Apoptosis of cultured granulosa-lutein cells is reduced by insulin-like growth factor I and may correlate with embryo fragmentation and pregnancy rate. Fertil Steril 85(2): 474-480.

3. Bodri D, Guillen JJ, Polo A, Trullenque M, Esteve C (2008) Complications related to ovarian stimulation and oocyte retrieval in 4052 oocyte donor cycles. Reprod. Biomed Online 17(2): 237-243.

4. D Loutradis, K Stefanidis, P Drakakis, An El Sheikh, S Milingos, et al. (2005) Comparison between "short" and "long" protocols in an ICSI programe. European Journal of Obstetrics \& Gynecology and Reproductive Biology 120(1): 69-72.

5. Daya S (2000) Gonadotropin releasing hormone agonist protocols for pituitary desensitization in in vitro fertilization and gamete intrafallopian transfer cycles. Cochrane Database Syst Rev 2: CD001299.

6. EB Baart, E Martini, MJ Eijkemans (2007) Milder ovarian stimulation for in-vitro fertilization reduces aneuploidy in the human preimplantation embryo: a randomized controlled trial. Human Reproduction 22(4): 980-988.

7. F Coelho, LF Aguiar, GSP Cunha, N Cardinot, E Lucena (2014) Comparison of Results of Cycles Treated with Modified Mild Protocol and Short
Protocol for Ovarian Stimulation. International Journal of Reproductive Medicine Article ID 367474.

8. Fauser BC, Nargund G, Andersen AN, Norman R, Tarlatzis B, et al. (2010) Mild ovarian stimulation for IVF: 10 years later. Hum Reprod 25(11): 2678-2684

9. Gottumukkala Achyuta Rama Raju, Rahul Chavan, Ameet Shashikant Patki, et al. (2013) Luteinizing hormone and follicle stimulating hormone synergy: A review of role in controlled ovarian hyper-stimulation. J Hum Reprod Sci 6(4): 227-234.

10. Hazout A, Ziegler Ade, Comel C, Fernandez N, Lelaidier C, et al. (1993) Comparison of short 7-day and prolonged treatment with gonadotropinreleasing hormone agonist desensitization for controlled ovarian hyperstimulation. Fertil Steril 59(3): 596-600.

11. Hill MJ, Levy G, Levens ED (2012) Does exogenous LH in ovarian stimulation improve assisted reproduction success. An appraisal of the literature? Reprod Biomed Online 24(3): 261-271.

12. Hughes EG, Federkow DM, Dayas S, Sagle MA, Van de Koppel P, et al. (1992) The routine use of gonadotropin-releasing hormone agonist prior to in vitro fertilization and gamete intrafallopian transfer: a metaanalysis of randomized controlled trials. Fertil Steril 58(5): 888-896.

13. Kotanidis L, Asimakopoulos B, Nikolettos N (2013) Association between $\mathrm{AMH}$, oocyte number and availability of embryos for cryopreservation in IVF. In Vivo 27(6): 877-880.

14. Loutradis D, Drakakis P, Kallianidis K, Milingos S, Dendrinos S, et al. (1999) Oocyte morphology correlates with embryo quality and pregnancy rate after intracytoplasmic sperm injection. Fertil Steril 72(2): 240-244.

15. Lunenfeld B (2004) Historical perspectives in gonadotrophin therapy. Hum Reprod Update 10(6): 453-467.

16. Michael M Alper, Bart C Fauser (2017) Ovarian stimulation protocols for IVF: is better than less? Reproductive biomedicine online 34(4): 345353.

17. Musters AM, van Wely M, Mastenbroek S, Kaaijk EM, Repping S, et al. (2012) The effect of recombinant LH on embryo quality: A randomized controlled trial in women with poor ovarian reserve. Hum Reprod 27(1): 244-250.

18. Practice Committee of American Society for Reproductive Medicine (2008) Gonadotropin preparations: past, present, and future perspectives. Fertil Steril 90(5-Supply): 13-20.

19. Ruvolo G, Bosco L, Pane A, Morici G, Cittadini E, et al. (2007) Lower apoptosis rate in human cumulus cells after administration of recombinant luteinizing hormone to women undergoing ovarian stimulation for in vitro fertilization procedures. Fertil Steril 87(3): 542546.

20. Steward RG, Lan L, Shah AA, Yeh JS, Price TM, et al. (2014) Oocyte number as a predictor for ovarian hyperstimulation syndrome and live birth: an analysis of 256,381 in vitro fertilization cycles. Fertil Steril 101(4): 967-973.

21. Verberg MF, Eijkemans MJ, Heijnen EM, Broekmans FJ, De Klerk C, et al. (2008) Why do couples' dropout from IVF treatment? A prospective cohort studies. Hum Reprod 23(9): 2050-2055. 


\section{ISSN: 2574-1241}

DOI: 10.26717/BJSTR.2019.18.003148

Mothanna Nazmi Jaber N. Biomed J Sci \& Tech Res

(C) (i) This work is licensed under Creative

Submission Link: https://biomedres.us/submit-manuscript.php

\begin{tabular}{ll} 
BIOMEDICAL & Assets of Publishing with us \\
RESEARCHES & - Global archiving of articles \\
& - Immediate, unrestricted online access \\
\hline isS: 2574-1241 & - Rigorous Peer Review Process \\
\end{tabular}

